\title{
TEMPORALIDADES INSCRITAS NO CORPO INTENSIVO DURANTE A EXPERIÊNCIA DO PROJETO ARTÍSTICO SOUNDSYSTEM
}

\author{
Priscilla Porto Nascimento Fasani
}

\begin{abstract}
Resumo
Este artigo debruça-se sobre o projeto artístico SoundSystem, desenvolvido por Franz Manata e Saulo Laudares desde 1996. O processo, em ação até os dias de hoje, consiste em partilhar experiências através de instalações sonoras, performances de DJ's e intervenções urbanas. São utilizados signos universais como batidas de coração e cantos de pássaros. A dupla assume uma preocupação ética de afetar o participante. As principais questões envolvidas são os "bons encontros", a dilação do tempo e a intensidade provocada pelos impulsos dionisíacos da música e da dança. Neste artigo, a proposta é viver o tempo do acontecimento, resistindo à cronopolítica.
\end{abstract}

\section{TEMPORALITIES EMBEDDED ON THE INTENSIVE BODY DURING THE EXPERIENCE OF THE ARTISTIC PROJECT SOUNDSYSTEM}

\begin{abstract}
This article addresses the artistic project SoundSystem, developed by Franz Manata and Saulo Laudares since 1996. The process, in action up to the present day, consists of sharing experiences through sound installations, DJ's performances and urban interventions. Universal signs such as heart beats and bird corners are used. The duo assumes an ethical concern to affect the participant. The main issues involved are the "good encounters", the time-dilation and the intensity provoked by the dionysian impulses of music and dance. This text will discuss the possibility of experience the time of the event, resisting to chronopolitics.
\end{abstract}

KeYwORDS

Affective encounters; body without organs; contemporary art; perceptions of time

Experimentar e interrogar é a minha maneira de avançar.

Sinto-me arrebatado, a minha alma dança. (Nietzsche) 


\section{INTRODUÇÃO}

Neste artigo, pensaremos a prática de construção de um corpo sem órgãos através das experiências partilhadas pelos artistas Franz Manata e Saulo Laudares nas obras Heartbeat (2006), The place (2010) e AFTER:Nature (2008). Estas instalações sonoras foram exibidas no Rio de Janeiro: no Parque Lage, na casa do curador Bernardo Mosqueira e ao ar livre, no Aterro do Flamengo, respetivamente. As sensações intensivas que podem ser sentidas durante estas exposições, provocam alterações nos circuitos de afetos, que permitem a criação de um corpo bailarino, que também dança às avessas. Os artistas resistem à cronopolítica e propõem um tempo do Acontecimento. A dança e a música permitem libertar o corpo de seus movimentos utilitários e orgânicos. Esta lógica da sensação acontece nestes encontros que vinculam os processos artísticos aos processos vitais, provocando a invenção de tempos outros, diferentes do tempo cronológico.

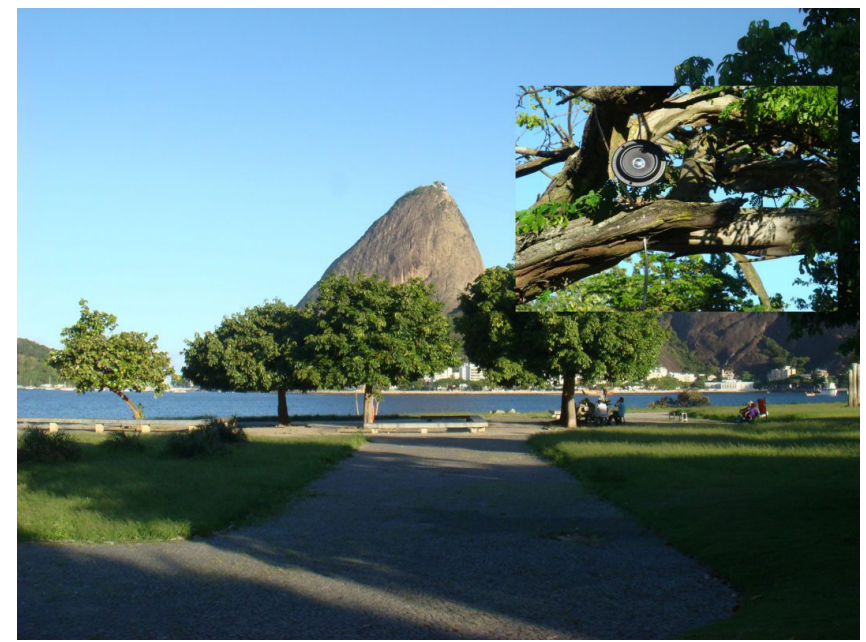

Figura 1: AFTER:Nature (2008) instalação sonora com tweeters, $150 \mathrm{~m}$ de cabos, potência, gerador, trilha

Créditos: Saulo Laudares

\section{A exposição Heartbeat}

A sensação experimentada durante a exposição da obra Heartbeat (2006), realizada nas Cavalariças do Parque Lage, no Rio de Janeiro, era de liberdade e de angústia ao mesmo tempo. O som vital dos batimentos cardíacos, que saíam das duas enormes caixas de som, faziam vibrar o meu corpo e não me era possível ficar isenta diante daquelas ondas de grave. Dava para se ver as estrelas e a noite. Esta experiência que começava no corpo, atingia outras linhas, outros estratos, fluxos, outras zonas de intensidade contínua, outros platôs. Parecia que o público estava ali para sentir e nada mais. Para tentar explicar esta sensação quase indescritível utilizarei as palavras de Nietzsche em Zaratustra, no aforismo Dos que desprezam o corpo: "eu sou corpo e alma - assim fala a criança" (Nietzsche, 1973, p. 38). 
Essa temporalidade aiônica que emana da partilha' da instalação sonora Heartbeat, um dos fragmentos do projeto SoundSystem, na qual se ouvia uma conversa entre os corações dos artistas Franz Manata e Saulo Laudares, numa pista de dança, me produziu um efeito que perdura por anos. Após senti-la era preciso pensar sobre esta experiência². O coração "é o órgão do desejo", da vida, do encontro, é uma pulsação desejante (Barthes, 2003, p. 91).

\section{ENCONTROS INTENSIVOS}

O momento em que a noção de partilha aparece no projeto SoundSystem foi em The Place, em 1998. The Place é um espaço de imersão aberto, em processo desde 1996, onde ocorrem manifestações que têm no outro o seu sentido de existência. O espaço pode se tornar uma pista de dança, um local de exposição ou palestras. A ideia inicial do The Place foi compartilhar a experiência da pista de dança e foi inspirada na obra Incidentes (Barthes, 2004), no texto No Palace, esta noite..., no qual Barthes descreve a sua experiência na boate francesa Le Palace que, na época, era considerada o templo da dança. Barthes, através de sua escrita, se remete à potência desse encontro. A partir de então, produzir a intensidade da experiência vivida por Barthes passou a ser o foco da dupla.

O próprio projeto surgiu a partir de um encontro dos artistas. Franz Manata e Saulo Laudares formam uma parceria artística e afetiva há mais de vinte anos. Ambos nasceram em Belo Horizonte, mas vivem no Rio de Janeiro desde o ano 2000. Franz Manata é professor da Escola de Artes Visuais do Parque Lage e curador independente. Trabalhou durante sete anos (2001-2008) como co-curador do Museu de Arte Moderna do Rio de Janeiro. Saulo Laudares é DJ de música eletrônica, além de desenvolver trilhas sonoras para espetáculos de dança e filmes. As obras dos artistas fizeram parte da galeria Artur Fidalgo, localizada em Copacabana e, mais recentemente, da Sé Galeria, que fica no centro de São Paulo.

Inspirados em Lygia Clark e Hélio Oiticica, propõem a participação do público. Oiticica e Clark colocaram a presença física do espectador no centro, superando a dissociação entre sentimento e saber, mente e corpo, do eu e do outro, do produtor e do consumidor (Salomão, 2015, p. 73). A perspetiva da vida como um laboratório de experimentações, de Oiticica, é um modo de vida que o duo tem como referência para a conceção de suas obras. Consequentemente, além de filhos de Oiticica, também são filhos de Nietzsche e Artaud (Salomão, 2015, p. 87). Quanto à influência de Lygia Clark, a noção de objeto relacional da artista fundamenta o trabalho da dupla, entretanto, os artistas quase nunca fazem uso de um objeto material, mas desta arte desmaterializada

\footnotetext{
' Para Jacques Ranciére, em A partilha do sensível (2005), partilha significa tanto a participação em um conjunto comum quanto, inversamente, a separação, a distribuição em quinhões. A partilha do sensível é um ato político e se refere a um encontro discordante de perceções individuais. Há um ritmo compartilhado e, ao mesmo tempo, um ritmo próprio de cada participante.

2 De acordo com Muniz Sodré (2016), etimologicamente, a palavra experiência vem do latim, experiri, e é formada por ex (fora), peri (perímetro, limite) e entia (aprender). Refere-se ao ato de aprender além dos limites, das fronteiras, há um deslocamento espacial, uma aventura, uma viagem, uma travessia, onde o mais importante é o processo, a duração, o devir.
} 
que é a música. Trata-se de uma arte relacional, que só existe no acontecimento que é o encontro com o outro.

Em Experiência e arte contemporânea (Kiffer, Bident \& Rezende, 2012), a noção de experiência é apresentada através de diferentes perspetivas. A experiência é algo que nos pode atravessar de um lado a outro, revolver-nos, transformar-nos sem que se possa nomeá-la; é algo que sobra, que excede a linguagem, que não pode ser contido e não tem onde caiba. A palavra experiência tem um duplo sentido: nomeia tanto uma prova pela qual se passou como a finalidade de produzir ou fomentar. A experiência é esse ponto de indeterminação entre o singular e o universal, entre o sensível e o inteligível, entre o prático e o teórico. Segundo Georges Bataille (1943), a experiência é um limiar, não é um acúmulo do vivido, aproximando-se mais do invisível e do não formulável, referindo-se a uma experiência interior, mas um interior retorcido, um interior exteriorizado ou um exterior interiorizado.

Segundo Claúdio Oliveira, no artigo "Do mesmo modo como queima o fogo ou da experiência como um saber que não se sabe", "a arte contemporânea talvez seja uma ocasião para nos reencontrarmos com o não saber constitutivo de nossa humanidade", de nos reencontrarmos com as sensações intensivas (Kiffer, Bident \& Rezende, 2012, p. 42). Afinal, a experiência - inclusive a do amor - nasce como uma rachadura no espelho, uma brecha na identidade de si e na ipseidade ou hecceidade 3 das coisas, aquilo que Deleuze chama de o inominável, o intempestivo, aquilo que não é uma forma, é um rizoma (Deleuze citado em Kiffer, Bident \& Rezende, 2012, p. 85).

No capítulo "Ensaio sobre a destruição da experiência, de infância e história “(Agamben, 2005), Agamben retoma o ensaio Experiência e pobreza de Benjamin (1933) e destaca que, para empobrecer a experiência do Homem, bastaria um cotidiano estressante, que atropela a temporalidade singular de cada um. A experiência, de acordo com Agamben, seria uma escada que leva a outros cômodos da casa, uma ferramenta que entremeia presente, passado e futuro (Agamben, 2005, p. 24).

\section{A CRIAÇÃo dE UM CORPO SEM ÓRGÃos}

A experiência de sentir o som dos batimentos cardíacos em Heartbeat, dissociados de uma imagem corpórea, remeteram-me ao conceito deleuziano de corpo sem órgãos (CsO). Esses corações não estavam ali "expostos" a fim de elucidarem a sua função fisiológica no corpo, cumprindo seu caráter utilitário no organismo. A intenção era partilhar um desejo de afetar e ser afetado. O duo, Manata e Laudares, assim como Guatarri e Deleuze, compartilham um modo de existência, um modo de vida, uma ética. Os autores/artistas não escrevem ou criam juntos, no mesmo ritmo, mas cada um no seu tempo e, assim, trabalham entre os dois, trata-se de uma dupla captura.

\footnotetext{
3 Daniel Lins, no artigo "Alegria como força revolucionária", explica que uma hecceidade é um modo de individuação específica que constitui individualidades novas e resiste à prisão identitária regida pelo pensamento ontológico, mediante a conexão de um conjunto de elementos heterogêneos materiais, os quais Deleuze nomeia de longitude e latitude, movimento e repouso, velocidade e lentidão, rizoma, não é uma forma, é uma entidade inédita e movediça (Furtado \& Lins, 2008, p. 52).
} 
Deleuze e Guatarri trabalham o conceito de $\mathrm{CsO}$, no terceiro volume de Mil Platôs (1996). O CsO é uma prática, uma experimentação, inspirada em Antonin Artaud, artista que buscou gerar, durante a experiência teatral, um corpo de resistência e intensidades, livre de automatismos e capaz de dançar. O Teatro da Crueldade enfatizava o sensível e as sensações, problematizando o excesso de racionalidade do mundo ocidental. $A$ crueldade para Artaud era a falta de liberdade (Lins, 1999, p. 12-13). Ao se esvaziar da sua funcionalidade, o corpo pode se abrir para o sensível, para o acontecimento.

Deleuze e Guatarri apropriam-se do conceito de $\mathrm{CsO}$ de Artaud para nomear a necessidade de criar um corpo liberto de sua função, considerando a lógica do capitalismo tardio, que prioriza a produtividade e controla o tempo dos indivíduos. O CsO é um corpo em acontecimento, em devir, um corpo capaz de experimentar sensações, de dançar, de sentir alegria e êxtase:

um $\mathrm{CsO}$ é feito de tal maneira que ele só pode ser ocupado, povoado por intensidades. Somente as intensidades passam e circulam, mas o CsO não é uma cena, um lugar, nem mesmo um suporte onde aconteceria algo. Nada a ver com um fantasma, nada a interpretar. (...) Ele não é espaço e nem está no espaço, é matéria que ocupará o espaço em tal ou qual grau. (Deleuze, 2007, p. 13)

A rotina corrida devido às demandas de produtividade no trabalho tende a anestesiar e dessensibilizar nossos corpos e é preciso recriá-los. Deleuze aponta a importância da experimentação, em oposição à interpretação da psicanálise (Deleuze, 2007, p. 11).

$\mathrm{Na}$ exposição Liberdade é pouco. O que desejo ainda não tem nome (2010) o curador Bernardo Mosqueira convidou artistas para pensarem sobre a liberdade na contemporaneidade e exporem seus trabalhos em sua casa no Jardim Botânico. A frase que intitula a exposição foi retirada da obra Perto do coração selvagem, de Clarice Lispector (1980, p. 50). Franz Manata e Saulo Laudares apresentaram The Place, que é a própria pista de dança como obra de arte. Num ambiente sonoro com a parede fluorescente, vários DJ's se revezavam no som. De acordo com Mosqueira, "a pista é lugar de atividade política: resistência, afeto, articulação, relação e criação. Fervo é Luta".

A obra Perto do coração selvagem (Lispector, 1980), assim como a obra de Manata e Laudares, trata do invisível, do indizível, das sensações que a personagem experimenta em seu corpo, em sua alma. Os conceitos de Spinoza, atravessam a obra, como a sua indistinção entre alma e corpo. Joana transgride o cotidiano repetitivo do tempo cronológico, brincando com o tempo do relógio. Ela vive o instante através da invenção de um tempo subjetivo. Joana cria para si um corpo sem órgãos, um corpo em devir que não possui uma identidade, nem um gênero definido, ele se constrói.

O sentido da ética de Spinoza, presente tanto na obra de Lispector quanto na do duo, é compor relações que aumentem a potência de agir e organizar encontros alegres que potencializem a força de existir. Spinoza não se surpreende em ter um corpo, mas com o que o corpo pode: "os corpos não se definem por seu gênero ou sua espécie, por seus órgãos e suas funções, mas por aquilo que podem, pelos afetos dos quais são capazes (Spinoza citado em Deleuze \& Parnet, 1998, p. 49). 
A questão que se coloca na obra de Manata e Laudares é como extrair alguma coisa alegre e apaixonante do que acontece, um clarão, um encontro, um acontecimento, uma velocidade, um devir (Deleuze \& Parnet, 1998, p. 54). Assim, o importante é fazer de um acontecimento, por menor que seja, a coisa mais delicada do mundo, dando ênfase às alianças, às núpcias, aos contágios, ao vento, ao quase-impercetível.

O corpo dos artistas resiste à cronopolítica, à política de controle do tempo, além de resistir à insensibilidade, às imposições de gênero e outras formas de domesticação do desejo. Os artistas desejam estar perto de um coração livre, selvagem.

\section{DANÇANDO Às AVESSAS}

Orlandi em "Corporeidades em minidesfile" (2004, p. 10), sublinha que os CsO ocorrem como imantações de linhas de fuga que acontecem nos instantes em que explodem sentidos, nos encontros em que se experimenta no corpo, as intensidades e a eternidade, nesse entretempo aiônico, o tempo da criança, da duração da vida. O CsO é o campo de imanência do desejo.

O teatro da crueldade de Artaud inaugura um teatro da não-representação, falando aos sentidos, ao sistema nervoso, à própria carne, à pele. Esse corpo pleno elaborado por Artaud, nem humano, nem metafísico, era um corpo de resistência e intensidades, um corpo sem órgãos. Este corpo refeito, reorganizado e liberto dos seus automatismos, se abre para dançar ao inverso. A dança é entendida como a libertação do corpo de seus movimentos utilitários, no direito e no avesso: "quando tiverem conseguido um corpo sem órgãos, então o terão libertado dos seus automatismos e devolvido sua verdadeira liberdade. Então poderão ensiná-lo a dançar às avessas como no delírio dos bailes populares e esse avesso será seu verdadeiro lugar" (Lins, 1999, p. 47).

Esta lógica da sensação (Deleuze, 2007), pensada por Deleuze, permite a unificação dos princípios opostos, o vivo e o morto, o desperto e o dormindo, o jovem e o velho, o amor e o ódio, a carícia e a agressão, o homem e a mulher. As fronteiras entre as artes são borradas. Nas artes plásticas ou na música, não se trata de reproduzir ou inventar formas, mas de captar as forças. É por este viés que nenhuma arte é figurativa. A obra de Manata e Laudares, ao acionar a música e a dança, busca tornar visíveis e sonoras as coisas que não são. A obra é imaterial e material ao mesmo tempo.

Em Lógica do sentido (Deleuze, 1974, p. 73), quando Deleuze relaciona a obra literária Alice no país das maravilhas com a teoria do sentido, menciona o corpo glorioso e sem órgãos, relacionando-o a Dionísio que mostra seus dois semblantes, seu corpo aberto e lacerado, sua cabeça impassível e sem órgãos, o Dionísio desmembrado, mas também impenetrável. O corpo sem órgãos é esse paradoxo da obra de Carrol, é essa intensidade, é esse limite. Saulo Laudares, ao falar da obra do duo, a relaciona ao "cair num buraco de Alice", referindo-se a estas sensações "incoerentes" do inconsciente, presentes em suas experimentações artísticas.

Podemos determinar qual o nosso poder de afetar e de ser afetado para que não vivamos ao acaso dos encontros. Se não sei do que meu corpo é capaz, de que o outro 
corpo com o qual me encontro é capaz, e como nossas relações podem se compor, vivo de maneira a recolher os efeitos destes encontros. Podemos ter o "modo de existência" que nos convenha, tal como demonstrou Spinoza (citado em Deleuze, 2002).

Em Mil platôs, no platô datado de 28 de novembro de 1947, intitulado "Como criar para si um corpo sem órgãos" (1996), Deleuze e Guatarri referem-se à data em que Artaud criou o conceito, que pode ser encontrado no poema Para acabar com o juízo de Deus. Nesta data, Artaud declara guerra aos órgãos (Deleuze \& Guatarri, 1996, p. 10). A questão apresentada é que não se trata de encontrar este corpo pronto em algum lugar; é preciso criá-lo. O corpo sem órgãos é um "exercício", não é uma noção, mas antes um conjunto de práticas, uma experimentação. "O corpo sem órgãos jamais se conclui" (Gadelha, 2010, p. 3).

Deleuze, em O ato de criação (1999) fala que as obras só se tornarão obras de arte se se tornarem atos de resistência. Elas resistem à aniquilação da vida e endereçam-se ao outro, a um outro que não existe (Deleuze, 1999, p. 91). A arte conserva, preservando um bloco de sensações, isto é, um composto de percetos e afetos. Os percetos são as perceções que ultrapassam o estado daqueles que os experimentaram e os afetos transbordam os sentimentos daqueles que os atravessaram (Deleuze \& Guatarri, 2005, p. 213). Afeto é experimentação, e não objeto de interpretação, o afeto é não-pessoal (Furtado \& Lins, 2008, p. 45). Em Diálogos (Deleuze \& Parnet, 1998), Deleuze aponta que o desejo não é privilégio de uma elite, é ele próprio um coletivo, um processo que exige um encontro, uma experiência, uma partilha.

A noção de corpo sem órgãos, nomeada por Artaud e utilizada por Deleuze e Guatarri, é também denominada corpo vibrátil (Rolnik, 2016), corpo pleno, corpo superior, corpo impossível, corpo novo, corpo não oprimido, corpo puro, corpo intensivo, corpo desejante, corpo intenso, corpo potente, corpo pulsante, corpo dionisíaco, corpo dançante, corpo que dança pelo avesso. Importando aqui a sua prática.

O que Deleuze e Guatarri propõem em O anti-édipo (2011) é uma desanálise, possibilitando captar a potência da droga sem se drogar ou a potência da loucura sem ser louco. A esquizoanálise é esse processo esquizo de descodificação e desterritorialização (Deleuze, 2013, p. 35). O intensivo é percebido como ato de resistência (Furtado \& Lins 2008 , p. 69) e a alegria como força revolucionária (Furtado \& Lins, 2008). A alegria nesse sentido é encantação, feitiço, estado de graça, errância. Trata-se de uma alegria vibrátil, um desejo de vida, a alegria-criança heraclitiana ou uma alegria bailarina (Furtado \& Lins, 2008, p. 49).

O som, em Heartbeat (2006), potencializa a criação desse $\mathrm{CsO}$, ao impelir o corpo a viver a experiência da dança. Conforme, escreveu o curador e crítico Guilherme Bueno:

Heartbeat investe no que se chamaria "plástica do som", isto é, da potência das ondas ser capaz de moldar, agir sobre o corpo do participante, conferindo uma corporeidade escultórica dada menos pelas características físicas particulares do espaço do que pelo quanto o som cria ali campos de força de atração ou repulsão, fazendo-nos tanto imergir hipnoticamente quanto em contrapartida sermos "obstruídos" naquele ambiente. (Bueno, 2012) 


\section{Circuitos de AFETos}

Como afirmou Safatle (2016), as sociedades são, em sua dimensão fundamental, circuitos de afetos. Elas constroem vínculos através da maneira com que os corpos são afetados, objetos sentidos e desejos impulsionados. Esses momentos raros nos quais acontecimentos nos fazem ser afetados de outra forma, quebram os circuitos de afetos que imperavam até então, nos despossuindo de nossos trajetos, nos desamparando de nossos ritmos e decompondo nossos corpos.

Quando Manata e Laudares convidam as pessoas a participarem de performances de DJ's, ver uma instalação com a palavra dancing em neon sem música, ouvir a instalação Heartbeat ou viver a experiência de contemplar a natureza e ouvir o canto dos pássaros durante a intervenção urbana AFTER:Nature, estão realizando uma arte do acontecimento. Aqui não importa produzir objetos que serão interpretados, mas experienciar o instante, o aiônico devir. Criar, portanto, não é apenas dar forma a uma matéria ou refletir sobre ela, mas erigir ritornelos, cristais de tempo, em materiais visuais, sonoros ou linguageiros (Zourabichvili, 2016, p. 148).

Na obra Deleuze: uma filosofia do acontecimento, Zourabichvili (2016) se remete à Lógica do sentido (Deleuze, 1974), onde Deleuze observou que não devemos nos perguntar qual é o sentido de um acontecimento, porque o acontecimento é o próprio sentido! E o acontecimento está nas coisas não visíveis ou não tangíveis, nas coisas abstratas como o espaço e o tempo.

A consistência do mundo está no afeto ou sensação; em outras palavras, ela está no acontecimento. Mas esse acontecimento não é do corpo, ainda que ele ocorra aos corpos; ele está no limite dos corpos, na passagem de um estado de coisas a outro (por exemplo, crescer). Assim, por ser o efeito incorpóreo de misturas de corpos, o acontecimento é expressável por natureza, o que torna a linguagem possível (Zourabichvili, 2016, p. 145).

Para que ocorram "disparações afetivas", novas maneiras de perceber, de sentir, de agir através da arte é preciso que algo "force" o pensamento, abale-o e o arraste numa busca, deve haver uma incitação casual que depende de um encontro (Zourabichvili, 2016, p. 51). E um encontro efetivo não é certamente fusional; é preciso uma arte das distâncias, nem muito perto, nem muito longe (Zourabichvili, 2016, p. 133).

\section{Tempos Aiônicos}

No ensaio "O que é o contemporâneo?" Agamben (2010) investiga o problema do tempo e aponta a necessidade da invenção de um outro tempo, diferente do tempo cronológico. É dessa experiência de invenção de uma outra temporalidade, de um ritmo próprio, de um encontro alegre consigo mesmo e com o outro que gostaríamos de tratar. A obra dos artistas Manata e Laudares flerta com essa questão ao propor uma dilatação e intensificação da experiência do tempo vivido.

Emília Araújo, em Quando o tempo desaparece (2007), reflete sobre essas questões dos ritmos do tempo capitalista e do tempo subjetivo. As ferramentas que marcam o 
tempo, como o relógio e o calendário, obrigam-nos a ter um certo ritmo, o qual regula a nossa vida. Os indivíduos não poderiam organizar seu dia-a-dia sem estarem seguros das formas de medição do tempo. Entretanto, em outros séculos, estes ritmos estavam desencontrados, pois cada sociedade possuía o seu próprio ritmo temporal. Mas, hoje, nenhuma sociedade sobrevive sem a orientação de um mesmo sistema temporal. Esta uniformização de ritmos faz com que as sociedades fiquem mais dependentes entre si, apesar das distâncias geográficas que as separam (Araújo, 2007, p. 21). Apesar da utilidade do calendário, a capacidade para avaliar a passagem do tempo está muito para além da aptidão para manusear todos estes instrumentos de medida. Possuímos a habilidade de sentir a passagem do tempo, que nos transforma o corpo e afeta nosso estado de espírito.

O tempo tal qual o espaço, é uma dimensão física, mas o tempo, diferentemente do espaço, é constituído do invisível. Verifica-se hoje uma acentuada impressão de aceleração do tempo. Os estudos realizados sobre os usos e a ocupação do tempo demonstram haver uma crescente "fome de tempo", resultado da celeridade dos ritmos de vida dos indivíduos. A pressa é uma constante, tudo deve ser rápido e com poucos intervalos de espera (Araújo, 2007, p. 24).

A concepção do tempo como algo exterior ao indivíduo, que este deve controlar e administrar, é um princípio da constituição da sociedade moderna. A ideia de uma cronologia abstrata e universal também. Isto faz parte do processo de colonização global do capital que precisa controlar o tempo dos indivíduos. Entretanto, é imperativo pressupor que ritmos distintos se desenrolam ao mesmo tempo (Araújo, 2007, p. 32).

Apesar de sua imaterialidade, o tempo tem uma profunda capacidade de afetar o comportamento das pessoas, e este tempo objetivo e comercializável tem consequências sobre a experiência subjetiva dos indivíduos, já que a falta de tempo leva ao stress, a sentimentos de impaciência e à ansiedade (Araújo, 2007, p. 37).

Os indivíduos, mesmo não estando sós, deixam de se sentir parte integrante de um todo. Além disso, há um adiamento de compromissos no plano biográfico e a redução da quantidade de tempo livre disponível. Não há dúvidas de que a administração do tempo se tornou uma questão política (Araújo, 2007, p. 43).

A necessidade de resistir à vigente cronopolítica ou à política de otimização do tempo justifica-se tendo em vista o mal-estar presente na contemporaneidade. O princípio do desempenho rege a performance do trabalhador que deve estar disponível em tempo integral, o que é viabilizado pelas novas tecnologias de comunicação. Há, dessa forma, uma recusa da temporalidade da experiência. De acordo com a filósofa Olgária Matos (2007), há este processo de alteração da temporalidade que se constitui através de uma aceleração do presente. A organização institucional do tempo faz com que cada um perca o sentido e o comando do tempo de sua vida. A impossibilidade de ter tempo para buscar um sentido para sua existência provoca no homem um sentimento de não pertencimento, de "sentir-se supérfluo", "um estranho no mundo". Dessa maneira, há um afrouxamento dos laços, que se tornam pouco duradouros. A pressa acentua a superficialidade dos vínculos, produzindo um empobrecimento interior; tendo em vista 
que os sentimentos exigem a duração para desenvolverem-se: "sem laços estáveis, produz-se um déficit simbólico no indivíduo e na sociedade, uma vez que valores dependem de um espaço comum de experiências compartilhadas" (Matos, 2007, p. 102).

Na obra A nau do tempo-rei (1993), na qual o filósofo Peter Pál Pelbart versa sobre o tempo da loucura, o autor busca repensar algumas de nossas clausuras temporais, estéticas e existenciais, brincando de desfazer certas ordens cristalizadas no espelho do tempo. O autor busca uma "leveza lúdica" capaz de reinventar o cotidiano. Pelbart cita Paul Virilio para falar de uma cronopolítica que está em curso e cujos desdobramentos ainda são desconhecidos, embora promova um achatamento temporal que proporciona um regime de temporalidade que tende a abolir a própria duração (Pelbart, 1993, p. 33). O autor pontua que enquanto a cronopolítica hegemônica visa à aceleração máxima, a loucura não só encarna uma desaceleração, mas a reivindicação de um outro tempo. E, sem dúvida, resgatar o "jorrar do tempo" é uma necessidade não só para a loucura, mas para a nossa vida e pensamento e pode se dar através da arte. A proposta dos artistas Manata e Laudares é inventar "ateliês de tempo", buscando um tempo dilatado, mais próximo da duração bergsoniana.

Este espaço reservado ao contra-tempo, ao intempestivo encontra-se em The Place, lugar de imersão imaginária, uma "máquina do tempo". Os artistas Manata e Laudares propõem momentos de resistência à violência intrínseca do frenético regime temporal vigente e buscam resgatar essa dimensão estética de experimentar a intensidade, promovendo uma espécie de "ritmanálise" (Pelbart, 1993), considerando a multiplicidade rítmica de cada sujeito. A música eletrônica permite mixar variadas vozes, evocar diversos tempos e temporalidades, onde todos são embalados pelo ritmo das batidas de um coração acelerado. Há aqui a proposta do "entre", de um "entrelugar" (Santiago, 2000) em que não se está na clausura da loucura, que possui um excesso do fora e de lentidão do tempo, nem totalmente dentro de um sistema acelerado que não abre espaço para a criação.

Os artistas buscam não o tempo pulsado do Chronos, mas o tempo flutuante da poiesis encontrado em Aion (Pelbart, 1993, p. 80). A essa tentativa de "partilha do sensível" (Rancière, 2005) ou do "como viver junto", Barthes (2003) denominou "idiorritmia", palavra composta do vocábulo ídios (próprio) e rhythmós (ritmo), que foi apropriada do universo religioso, mas que pode se estender ao mundo profano. Dessa forma, apesar de viver em comunidade, o ritmo de cada um pode ter vez. Quando se refere à duração da vida, da vitalidade, do aion, o filósofo pré-socrático Heráclito diz: "duração da vida é uma criança brincando, movendo peças em um jogo. A realeza é da criança" (Kahn, 2009, p. 95). E Nietzsche acrescenta: "é que a criança é inocência e esquecimento, um novo começar, um brinquedo" (Nietzsche, 1973, p. 31).

Em Lógica do sentido (Deleuze, 1974, pp. 90-93), no capítulo “Do aion", Deleuze discorre a respeito destas duas dimensões do tempo, a de Cronos e a de Aion. De acordo com Cronos, só o presente existe no tempo e este presente é de alguma maneira corporal. Segundo Aion, somente o passado e o futuro insistem ou subsistem no tempo. Enquanto Cronos exprimia a ação dos corpos e a criação das qualidades corporais, Aion é o lugar dos acontecimentos incorporais. Enquanto Cronos era inseparável dos corpos 
que o preenchiam, Aion é povoado de efeitos que o habitam sem nunca preenchê-lo. Este presente do Aion, que representa o instante é o presente do ator, do dançarino. $\mathrm{O}$ aion é "subtrair-se da cronologia sem saltar para um além" (Pelbart, 2008, p. 22).

Que é, pois, o tempo? É o conectar imediato dos heterogêneos, é simultaneamente o anônimo e o individuante, o impessoal e fonte de toda a identidade (Zourabichvili, 2016, pp. 108-109). O tempo, para Deleuze, não é aquele que valoriza a conexão de sucessão, é um tempo heterogêneo, é o tempo do Acontecimento (Zourabichvili, 2016, p. 99). Num mesmo organismo, cada órgão possui seu presente e sua duração própria, de modo que nele coexistem vários presentes, durações ou velocidades relativas. Assim sendo, cada um de nós vive simultaneamente em várias linhas do tempo, sendo que algumas linhas se esfumam e se interrompem brutalmente, ao passo que outras se afirmam. O presente não dá conta de sua própria passagem (Zourabichvili, 2016, p. 101). 0 terceiro modo do tempo pensado por Deleuze é uma temporalidade que não privilegia nem o presente, nem o passado, mas o futuro; tudo o que existe está em devir (Zourabichvili, 2016, p. 106).

\section{AFTER:NATURE}

Um encontro, como o acontecimento em AFTER:Nature (2008), possibilita se arrebatar para uma nova dimensão temporal. Esta instalação sonora acusmática, em que não se via a fonte do som, reproduzindo uma trilha composta por sons de cantos de pássaros, aconteceu em pleno Aterro do Flamengo, no Rio de Janeiro. O projeto consistiu na instalação de 42 tweeters na copa de cinco árvores. Nesta obra, os artistas desejaram atrair as pessoas para esse lugar transmutador, propuseram uma desaceleração no caos urbano, instigaram o passante a desfrutar dos sons dos cantos dos pássaros e até permitiram aos mais desatentos descobrir, através de "falhas" na trilha e outros ruídos, de que se tratava de um artifício ou dispositivo. Nas palavras do curador Eduardo Campos sobre a intervenção urbana: "na polifonia das cidades, o canto dos pássaros funciona como som atávico, fazendo-nos lembrar nostalgicamente da natureza, da anticivilização, da perda do paraíso" (Campos, 2008, p. 15). A obra pontua um entrelugar, um entretempo, situando-se como uma obra de passagem.

Podemos pensar nesta obra como um arquivo, um locus da memória, dos registros do passado (Derrida, 2001), um "bloco mágico", um brinquedo de criança, que aciona sensações adormecidas na nossa memória e revela que a emergência do correio eletrônico e de outras formas de comunicação, transformaram nossa maneira de viver e de nos relacionar com os espaços públicos e privados. Há também a intenção de reinventar o cotidiano e transfigurar o lugar comum. Trata-se de uma desnaturalização do ordinário, o que os franceses chamam de dépaysement, expressão que descreve o deslocamento de um lugar para outro e seus efeitos advindos das mudanças de hábitos e de ambiente (Bueno, 2012). Quando os artistas mimetizam o som do canto dos pássaros, enfatizam o seu poder de nos permitir sentir e ativar perceções anestesiadas pelo cotidiano apressado da cidade. 
Esse tempo eterno, com vagar, tempo prazeroso, sem horários apressados, sem obrigações, refere-se a um gozo de tempo sem imediatez, numa outra curtição do tempo, uma maneira de fruir o tempo diferente do tempo do capitalismo, como afirma Waly Salomão, "é o time is pleasure", é o reinado do prazer e a suspensão do princípio de realidade, nem que seja por alguns instantes (Salomão, 2015, p. 90).

A esfera de duração vivida pela música não se refere a um período de tempo - 10 minutos, meia hora ou uma fração do dia - mas a um tempo experienciado, ao "agora", a uma passagem da vida que sentimos. Tal passagem é mensurável apenas em termos de sensibilidades, tensões e emoções. Nossa vida é medida pelo ritmo, pela respiração e pela pulsação. Ouvir música pode promover um estado "fora do tempo" (Langer, 2011, p. 28). De acordo com Langer, sempre que sentimos, estamos na presença da arte, da experiência estética (Langer, 2011, pp. 116-117).

Nossa apropriação do espaço é sonora. Reconhecemos ruídos e os sons mais diversos e construímos nossa memória afetiva a partir dos sons domésticos, por exemplo. Barthes anuncia que o "ford-da" freudiano, marca o nascimento da linguagem, quando a criança experimenta a ausência e a presença da mãe com um jogo que consiste em lançar e retomar um carretel amarrado num barbante, criando não só o primeiro jogo simbólico, mas também o ritmo (Barthes, 1990, p. 220). Barthes também diferencia ouvir, que é um fenômeno fisiológico, de escutar, que é um ato psicológico (Barthes, 1990, p. 217). E cada um possui a sua sinfonia pessoal, construída através das experiências.

\section{FRAGMENTOS FINAIS}

Manata e Laudares lançam na contemporaneidade pequenas luzes, como vaga-lumes, que possuem luz própria, mas precisam do outro para conseguir iluminar uma porção maior do seu tempo. Sua arte, através do dispositivo da música, desperta esses seres dançantes e cheios de vitalidade, proporcionando lampejos, "ao mesmo tempo eróticos, alegres e inventivos" (Didi-Huberman, 2011, p. 20), uma espécie de "exceção da alegria inocente" (Didi-Huberman, 2011, p. 21) num mundo em que o tempo é tão acelerado e sem muito tempo para a poesia. Esse lugar crucial "onde a política se encarnaria nos corpos, nos gestos e nos desejos de cada um (Didi-Huberman, 2011, pp. 24-25) é sem dúvida um movimento de resistência, talvez muito frágil e sutil, mas necessário para iluminar a nossa noite. Quando Pasolini escreveu sobre os vaga-lumes referiu-se ao desaparecimento do humano no coração da sociedade atual, ele se referia a um mal-estar na cultura. Didi-Huberman nesta obra intitulada Sobrevivência dos vagalumes (2011) faz uma interferência neste tempo apocalíptico e propõe uma "política de sobrevivências", de percepção da "nova beleza de uma coreografia", de uma invenção de formas, de "redescobrir a infância do olhar sobre todas as coisas" que possam emitir "parcelas de humanidade" (Didi-Huberman, 2011). 


\section{REFERÊNCIAS}

Agamben, G. (2005). Infância e história: destruição da experiência e origem da história. Belo horizonte: Editora UFMG.

Agamben, G. (2010). O que é o contemporâneo? In G. Agamben, Nudez (pp. 19-29). Lisboa: Relógio D’ Água.

Araújo, E. (2007). O desaparecimento do tempo nas sociedades modernas. In E. Araújo \& A. Duarte (Eds.), Tempo e simultaneidade: o desaparecimento do tempo (pp.21-47). Porto: eCopy.

Barthes, R. (2003). Como viver junto: simulações romanescas de alguns espaços cotidianos: cursos e seminários no Collège de France, 1976-1977. São Paulo: Martins Fontes.

Barthes, R. (2004). Incidentes. São Paulo: Martins Fontes.

Barthes, R. (1990). O óbvio e o obtuso. Rio de Janeiro: Nova Fronteira.

Bataille, G. (1943). L'expérience intérieure. Paris: Gallimard.

Bueno, G. (2012, agosto). Franz Manata e Saulo Laudares. Dasartes, 23. Retirado de http://dasartes.com.br/ materias/franz-manata-e-saulo-laudares/

Campos, M. (2008). AFTER: Nature. In Catálogo Interferências Urbanas, prêmio 2008.

Deleuze, G. (1974). Lógica do sentido. São Paulo: Perspectiva, Ed. da Universidade de São Paulo.

Deleuze, G. (1999). O ato de criação. Palestra de 1987. Edição brasileira: Folha de São Paulo.

Deleuze, G. (2002). Espinosa uma filosofia prática. São Paulo: Editora Escuta.

Deleuze, G. (2007). Francis Bacon - lógica da sensação. Rio de Janeiro: Zahar.

Deleuze, G. (2013). Conversações. São Paulo: Editora 34.

Deleuze, G. \& Guatarri, F. (1996). Mil platôs: capitalismo e esquizofrenia, vol. 3. São Paulo: Ed. 34.

Deleuze, G. \& Guatarri, F. (2005). O que é filosofia? Rio de Janeiro: Ed. 34.

Deleuze, G. \& Guatarri, F. (2011). O anti-Édipo: capitalismo e esquizofrenia. São Paulo: Ed. 34.

Deleuze, G. \& Parnet, C. (1998). Diálogos. São Paulo: Escuta.

Derrida, J. (2001). Mal de arquivo: uma impressão freudiana. Rio de Janeiro: Relume Dumará.

Didi-Huberman, G. (2011). Sobrevivência dos vagalumes. Belo Horizonte: Editora UFMG.

Furtado, B. \& Lins, D. (Eds.). (2008). Fazendo rizoma. São Paulo: Hedra.

Gadelha, C. (2010). A respeito de modernos e contemporâneos. Anais VI Congresso da ABRACE, 11(1), 1-5. Retirado de https://www.publionline.iar.unicamp.br/index.php/abrace/article/view/3358/3516

Kahn, C. (2009). A arte e o pensamento de Heráclito. São Paulo: Paulus.

Kiffer, A., Bident, C. \& Rezende, R. (ORG). (2012). Experiência e arte contemporânea. Rio de Janeiro: Editora Circuito.

Langer, S. K. (2011). Sentimento e forma: uma teoria da arte desenvolvida a partir de filosofia e nova chave. São Paulo: Perspectiva. 
Lispector, C. (1980). Perto do coração selvagem. Rio de Janeiro: Editora Nova Fronteira.

Lins, D. (1999). Antonin Artaud, o artesão do corpo sem órgãos. Rio de Janeiro: Relume Dumará.

Matos, O. (2007). O mal-estar na contemporaneidade: performance e tempo. In M. Medeiros, M. Monteiro, \& T. Matsumoto (Eds.), Tempo e performance (pp. 11-20). Brasília: Editora de Pós-graduação em Arte da Universidade de Brasília.

Nietzsche, F. (1973). Assim falou Zaratustra. Lisboa: Guimarães Editores.

Orlandi, L. (2004). Corporeidades em minidesfile. Retirado de http://www.pucsp.br/nucleodesubjetividade/ Textos/orlandi/corporeidade_minidesfiles.pdf

Pelbart, P. P. (1993). A nau do tempo-rei: sete ensaios sobre o tempo da Loucura. Rio de Janeiro: Imago.

Pelbart, P. P. (2008). O tempo não-reconciliado: imagens de tempo em Deleuze. São Paulo: Perspectiva.

Rancière, J. (2005). A partilha do sensível: estética e política. São Paulo: Editora 34.

Rolnik, S. (2016). Cartografia sentimental: transformações contemporâneas do desejo. Porto Alegre: Editora Sulina; Editora da UFRGS.

Safatle, V. (2016). O circuito dos afetos: corpos políticos, desamparo e o fim do indivíduo. Belo Horizonte: Autêntica.

Salomão, W. (2015). Hélio Oiticica: qual é o parangolé? São Paulo: Companhia das Letras.

Santiago, S. (2000). Uma literatura nos trópicos. Rio de Janeiro: Rocco.

Sodré, M. (2016, agosto). Educação e diversidade [Palestra]. UFBA, dia 29 de agosto de 2016, Salvador, BA.

Zourabichvili, F. (2016). Deleuze: uma filosofia do acontecimento. São Paulo: Editora 34.

\section{Nota BiográficA}

Priscilla Porto Nascimento Fasani é doutorada em Cultura e Sociedade pela Universidade Federal da Bahia (2019), mestre em Ciência da Arte pela Universidade Federal Fluminense (2006) e graduada em Comunicação Social pela Pontifícia Universidade Católica do Rio de Janeiro (2000). Publicou o livro A relação ética da arte na sociedade do espetáculo pela Editora da UFF (2007). É integrante do grupo de pesquisa Ecus da UFBA desde 2015 .

ORCID: https://orcid.org/0000-0002-1521-1818

Email: priscillafasani@hotmail.com

Morada: Rua do Mangalo 277 - apto 102 - Patamares - Cep. 41.680-048 - Salvador - Bahia - Brasil

* Submetido: 01/09/2018

* Aceite: 10/2/2019 